Rabaska

Revue d'ethnologie de l'Amérique française

DUPUIS, SERGE. Plus peur de l'hiver que du Diable. Une histoire des Canadiens français en Floride. Sudbury, Prise de parole, "Agora ", 2016, 180 p. ISBN 9782894239520

\title{
Rémy Tremblay
}

Volume 14, 2016

URI : https://id.erudit.org/iderudit/1037473ar

DOI : https://doi.org/10.7202/1037473ar

Aller au sommaire du numéro

Éditeur(s)

Société québécoise d'ethnologie

ISSN

1703-7433 (imprimé)

1916-7350 (numérique)

Découvrir la revue

Citer ce compte rendu

Tremblay, R. (2016). Compte rendu de [DUPUIS, SERGE. Plus peur de l'hiver que du Diable. Une histoire des Canadiens français en Floride. Sudbury, Prise de parole, " Agora », 2016, 180 p. ISBN 9782894239520]. Rabaska, 14, 244-245.

https://doi.org/10.7202/1037473ar d'utilisation que vous pouvez consulter en ligne.

https://apropos.erudit.org/fr/usagers/politique-dutilisation/ 
Dupuis, Serge. Plus peur de l'hiver que du Diable. Une histoire des Canadiens français en Floride. Sudbury, Prise de parole, «Agora », 2016, 180 p. ISBN 9782894239520.

Il y a déjà plusieurs décennies que l'Amérique française fait l'objet de recherches universitaires. D'innombrables articles scientifiques, livres, mémoires, thèses, conférences lui ont été dédiés et on le fera encore longtemps même si certains pourraient prétendre que tout a été écrit sur les francophones de la Nouvelle-Angleterre et de la Louisiane, par exemple. Aussi, plus d'un croit que l'espace francophone nord-américain a été couvert en entier par les chercheurs. Est-ce vraiment le cas ? Pas tout à fait.

En effet, si certains foyers francophones hors Québec ont reçu beaucoup d'attention, d'autres peu, voire pas du tout. C'est le cas des Canadiens français en Floride. À l'instar de médias québécois, canadiens-anglais, français et même étatsuniens, un nombre infime d'universitaires se sont penchés sur cet îlot franco-américain. Serait-ce par snobisme ? Quoi qu'il en soit, à ce jour, Plus peur de l'hiver que du Diable de Serge Dupuis est le troisième livre publié sur la présence canadienne-française dans l'État du soleil, après Tremblay et Desrosiers-Lauzon ${ }^{3}$. C'est trop peu pour cette communauté nouveau genre qui a tant à offrir pour comprendre l'(im)migration des Canadiens français à l'ère des médias sociaux et de la grande mobilité transnationale des individus et des groupes.

Et l'ouvrage de Serge Dupuis ne déçoit pas. Loin de là ! D'une part, il y a la couverture qui est irrésistible. Sur un fond turquoise se trouve le motel le plus iconique de la Floride canadienne-française, le Richard's Motel (une visite du site web de l'établissement s'impose), entouré de palmiers, des drapeaux américain et québécois, d'un crocodile, etc. La table est donc mise. D'autre part, le contenu de l'ouvrage de Serge Dupuis est solide : les sources bibliographiques, documentaires, web, etc. sont nombreuses, bien fouillées et très pertinentes.

Divisé en cinq chapitres, avec introduction et conclusion, le chercheur commence avant tout par une note d'environ deux pages définissant le vocable « Canadien-français ». Il s'agit là d'une sage décision puisque le concept est on ne peut plus galvaudé. En introduction, on contextualise la Floride dans le cadre géographique et historique de l'Amérique française. Au chapitre premier, Dupuis brosse un tableau formidable de la colonisation de la Floride et de la présence francophone dans cet État américain. Le travail est colossal puisque très peu de travaux portent sur le sujet. En fait, à part DesrosiersLauzon, ce qui a été écrit sur le sujet se voulait très superficiel ou datait de

3. Rémy Tremblay, Floribec, Ottawa, Presses de l'Université d'Ottawa, 2006, 168 p. ; Godefroy Desrosiers-Lauzon, Florida's Snowbirds. Montréal/Kingston, McGill-Queen's University Press, 2011, $376 \mathrm{p}$. 
quelques décennies. Le deuxième chapitre traite de l'évolution de l'industrie touristique en Floride tout en faisant un lien avec la présence des touristes canadiens-français. La belle iconographie, les sources solides et le détail dans la chronologie de cette économie indispensable de la Floride montrent bien que l'auteur, un historien, maîtrise fort bien son sujet. Le chapitre trois est consacré à l'immigration canadienne-française en Floride. Encore une fois, la perspective historique domine appuyée de cartes, de tableaux et de données statistiques solides. Le chapitre suivant aborde la question des hivernants en utilisant une approche similaire au chapitre précédent. Au dernier chapitre, il est question des descendants canadiens-français dans cet État du Sud. Ce chapitre est intéressant puisqu'il aborde également toutes ces migrations hispanophones, entre autres, qui continuent de façonner la Floride.

Bref, Serge Dupuis nous offre un ouvrage incontournable sur la Floride canadienne-française. Il se veut concis, précis, solide et convaincant. Permettrat-il enfin aux spécialistes de la francophonie nord-américaine de cesser de bouder ce noyau franco-américain si précieux ? La grande qualité de ce troisième ouvrage sur le sujet devrait mettre l'eau à la bouche aux chercheurs et enchanter le grand public.

Rémy Tremblay

TéLuQ, Université du Québec

Durand, Guy, avec la collaboration de Jocelyne Massé. Fêtes, traditions et symboles chrétiens : pour comprendre la culture québécoise. Montréal, Fides, 2014, 277 p. ISBN 978-2-7621-3762-0.

Voici un livre attrayant, qui attire l'attention en librairie. Sujet pertinent, couverture chatoyante, table de matières invitante. En préambule, Jésus et le christianisme, puis trois parties : une première, générale, sur le temps, les institutions, les fêtes et les symboles ; la deuxième, la plus développée, sur les deux cycles de Noël et de Pâques; et une troisième sur le culte des saints. L'auteur est bien connu : spécialiste de l'éthique, puis de la bioéthique, il a pris sa retraite de l'Université de Montréal en 1997 et produit depuis lors à peu près un livre par année. Maintenant octogénaire, il publie ce livre-ci en collaboration avec son épouse Jocelyne Massé. Ils le dédient à leurs enfants et petits-enfants, l'objectif principal étant de « faire connaître la part chrétienne (événementielle et symbolique) de la culture québécoise, voire occidentale ». Mais ils veulent aussi que le livre puisse contribuer à leur « ressourcement culturel et spirituel».

Le traitement est plutôt classique, voire traditionnel : le sujet s'y prête. L'auteur s'inspire de différents ouvrages, qui lui permettent de présenter 